\title{
Some remarks on the seismic behaviour of embedded cantilevered retaining walls
}

\author{
R. CONTI*, G. M. B. VIGGIANI† and F. BURALI D’AREZZO
}

\begin{abstract}
This paper is a numerical investigation of the physical phenomena that control the dynamic behaviour of embedded cantilevered retaining walls. Recent experimental observations obtained from centrifuge tests have shown that embedded cantilevered retaining walls experience permanent displacements even before the acceleration reaches its critical value, corresponding to full mobilisation of the soil strength. The motivation for this work stems from the need to incorporate these observations in simplified design procedures. A parametric study was carried out on a pair of embedded cantilevered walls in dry sand, subjected to real earthquakes scaled at different values of the maximum acceleration. The results of these analyses indicate that, for the geotechnical design of the wall, the equivalent acceleration to be used in pseudo-static calculations can be related to the maximum displacement that the structure can sustain, and can be larger than the maximum acceleration expected at the site. For the structural design of the wall, it is suggested that the maximum bending moments of the wall can be computed using a realistic distribution of contact stress and a conservative value of the pseudostatic acceleration, taking into account two-dimensional amplification effects near the walls.
\end{abstract}

KEYWORDS: design; earth pressure; earthquakes; numerical modelling; retaining walls; shear strength

\section{INTRODUCTION}

In the recent literature several cases are reported of damage or failure of gravity and cantilevered retaining walls during earthquakes (Fang et al., 2003; Madabhushi \& Zeng, 2007; Koseki et al., 2012). Following the pioneering works by Okabe (1926) and Mononobe \& Matsuo (1929), several studies have tackled the problem of computing dynamic earth pressures on retaining structures with a theoretical (Steedman \& Zeng, 1990; Lancellotta, 2007; Mylonakis et al., 2007; Kim et al., 2010), experimental (Atik \& Sitar, 2010) or numerical approach (Gazetas et al., 2004; Evangelista et al., 2010). In the last decade, following the seminal works by Newmark (1965) and Richards \& Elms (1979), more and more works have been devoted to the computation of wall displacements, in the light of a performance-based design (Ling, 2001; Huang et al., 2009; Basha \& Babu, 2010).

In recent years, new performance-based strategies have been proposed in the literature and included in current codes of practice (PIANC, 2001; CEN, 2003; NTC, 2008) for the seismic design of retaining structures. Although characterised by different levels of complexity, all these methods rely on the idea that the structure may experience permanent displacements during the earthquake, provided the behaviour of the system is ductile.

The simplest way to embody the performance-based philosophy in the seismic design of retaining structures is by an appropriate choice of the equivalent acceleration to be used in pseudo-static calculations, which has to be proportional to the maximum acceleration expected at the ground surface,

Manuscript received 19 February 2013; revised manuscript accepted 11 July 2013.

Discussion on this paper is welcomed by the editor.

* Dipartimento di Ingegneria Civile, Università di Roma Tor Vergata, and International School for Advanced Studies, Trieste, Italy.

$\dagger$ Dipartimento di Ingegneria Civile, Università di Roma Tor Vergata, Italy.

$\$$ University of Cambridge, UK. either provided by the technical codes or obtained by onedimensional seismic response analyses.

If the permanent displacement at the end of the earthquake is taken as a performance indicator, the choice of the equivalent acceleration should be related to the maximum displacements that the structure can sustain, with respect to different levels of design earthquake motion. The reliability of the choice of an equivalent acceleration depends crucially on the ability to predict the displacements experienced by the wall during the earthquake.

Permanent displacements of retaining walls are usually computed through Newmark (1965) rigid-block analysis (Richards \& Elms, 1979). According to this method

(a) the critical (yield) acceleration of the wall, $a_{\mathrm{c}}$ - that is, the acceleration corresponding to which the strength of the soil is fully mobilised - is computed with respect to an assumed collapse mechanism, assuming rigidperfectly plastic behaviour for both the soil and the wall

(b) for accelerations $a(t) \leqslant a_{\mathrm{c}}$, no relative displacements occur between the soil and the wall, and both the inertia forces into the soil wedge-wall system and the internal forces in the structure increase with the applied accelerations

(c) for accelerations $a(t)>a_{\mathrm{c}}$, the wall experiences permanent displacements, but the internal forces remain constant and equal to the maximum value they attained for $a(t)=a_{\mathrm{c}}$

(d) the permanent displacements are computed by integrating the relative acceleration, $a(t)-a_{\mathrm{c}}$, twice over the time intervals in which the relative velocities are non-zero.

The critical acceleration is a key ingredient not only for the computation of the permanent displacements experienced by the wall, but also for its structural design, as it defines the maximum internal forces that the structure may ever experience during an earthquake.

Centrifuge dynamic tests have shown that Newmark rigidblock analysis provides good results when applied to gravity retaining structures (Zeng \& Steedman, 2000; Huang et al., 2009). Moreover, experimental dynamic tests carried out on 
reduced-scale models (Neelakantan et al., 1992; Richards \& Elms, 1992) and dynamic numerical analyses (Callisto \& Soccodato, 2010) have shown that a Newmark-type calculation may also be adopted, at least qualitatively, to interpret the dynamic behaviour of embedded cantilevered walls or retaining walls with one level of support, where the wall can rotate when a state of limit equilibrium is attained in the adjacent soil.

Results from both numerical (Callisto \& Soccodato, 2007, 2010) and experimental (Zeng, 1990; Zeng \& Steedman, 1993; Conti et al., 2012) work on the dynamic behaviour of embedded retaining walls, however, have shown that the Newmark approach does not describe the observed behaviour satisfactorily. In fact, if the critical acceleration of the system is computed with standard limit equilibrium methods, such as those adopted in European countries and the USA (Blum, 1931; Padfield \& Mair, 1984; King, 1995; Powrie, 1996; Day, 1999; Osman \& Bolton, 2004), seeking the pseudo-static coefficient corresponding to which limit conditions are attained in the system, two findings are of major concern.

(a) Embedded walls may accumulate significant rigid permanent displacements concurrently with an increase of the internal forces in the structural members: that is, permanent displacements occur even before the critical acceleration is attained.

(b) Internal forces in cantilevered walls may be substantially larger than those computed with conventional limit equilibrium methods in critical conditions.

It follows that, at least for cantilevered walls, standard pseudo-static approaches do not provide reliable or conservative values of the yield acceleration, neither for a displacement-based analysis nor for a pseudo-static calculation.

On the basis of centrifuge dynamic tests carried out on pairs of embedded propped and cantilevered walls in dry sand, Conti et al. (2012) have shown that a Newmark analysis carried out using the limit equilibrium value of the critical acceleration would yield displacements that are much smaller than observed, as the analysis would overlook the displacements experienced by the wall before the acceleration reaches the limit equilibrium critical value. According to the authors, the observed behaviour may be justified by a stress redistribution and a progressive mobilisation of the soil strength on the passive side of the wall produced by the earthquake.

Recent numerical studies of the dynamic behaviour of embedded retaining walls, both cantilevered (Madabhushi \& Zeng, 2006, 2007) and with one level of support (Iai \& Kameoka, 1993; Callisto et al., 2008; Cilingir et al., 2011) have shown interesting aspects related to the soil-structure interaction and the constitutive modelling of the mechanical behaviour of the soil under cyclic loading. Useful guidelines for the seismic design of cantilevered retaining walls may be found in Callisto \& Soccodato (2010), but these are still not exhaustive: the simplified procedure proposed by the authors does not seem conservative, as it is based on a standard pseudo-static calculation of the critical acceleration.

This work is a numerical investigation of the physical phenomena that control the dynamic behaviour of embedded cantilevered retaining walls, aimed at developing suitable simplified procedures to be incorporated in recommendations and codes of practice. A parametric study was carried out on a pair of embedded cantilevered walls in dry sand, subjected to real earthquakes scaled at different values of the maximum acceleration. The earthquakes were chosen to represent a significant range of dominant frequency (governing local amplification and resonance phenomena) and peak acceleration (governing non-linearity of soil behaviour and mobilisation of plastic strain). Based on the results of the parametric study, suggestions are provided for the seismic geotechnical and structural design of embedded cantilevered walls using simplified methods.

\section{ANALYSIS PROCEDURE \\ Constitutive soil model}

The soil is modelled as an elastic-perfectly plastic material with Mohr-Coulomb failure criterion, in which, during the dynamic stage, non-linear and hysteretic behaviour is introduced for stress paths within the yield surface through a hysteretic model available in the library of FLAC 5.0 (Itasca, 2005). This strategy makes it possible to take into account both the cyclic soil behaviour and the possibility of full mobilisation of soil strength close to the excavation, at the same time avoiding the cumbersome calibration process and the high computational costs of more advanced constitutive models (Kontoe et al., 2012).

The hysteretic model, which is used to update the tangent shear modulus of the constitutive law for the soil at each calculation step, consists in an extension to general strain conditions of the one-dimensional non-linear models that make use of the Masing (1926) rules to describe the unloading-reloading behaviour of soil during cyclic loading. If the simplified assumption is made that the stress state does not depend on the number of cycles, the relationship between shear stress, $\tau$, and shear strain, $\gamma$, can be written as

$$
\begin{aligned}
\tau & =G_{\mathrm{S}}(\gamma) \cdot \gamma \\
& =G_{0} M_{\mathrm{S}}(\gamma) \cdot \gamma
\end{aligned}
$$

where $G_{\mathrm{S}}(\gamma)$ is the secant shear modulus, $G_{0}$ is the smallstrain shear modulus, and $M_{\mathrm{S}}(\gamma)$ is the normalised secant shear modulus, defined as

$$
M_{\mathrm{S}}=\frac{a}{1+\exp \left[-\left(\log _{10} \gamma-x_{0}\right) / b\right]}
$$

where $a, b$ and $x_{0}$ are model parameters that can be determined from the best fit of a specific modulus degradation curve. The tangent shear modulus, $M_{\mathrm{t}}$, can be evaluated by differentiating equation (1) with respect to $\gamma$. Strain reversals during cyclic loading are detected by a change of the sign of the scalar product between the current strain increment and the direction of the strain path at the previous time instant. At each strain reversal, the Masing rule is invoked, and stress and strain axes are scaled by a factor of $0 \cdot 5$, resulting in hysteresis loops in the stress-strain curves with associated energy dissipation.

As already outlined by Callisto \& Soccodato (2010), an advantage of using a truly non-linear soil model for dynamic numerical simulations is that energy dissipation emerges from the hysteretic behaviour of the soil, and is not introduced artificially by including a frequency-dependent viscosity in the equilibrium equations.

\section{Seismic input}

Three different acceleration time histories were used in the analyses, all registered on rock outcrop during real earthquakes: Tolmezzo (T) from the Friuli earthquake of 1976, Assisi (A) from the Umbria-Marche earthquake of 1997, and Arcelik (N) from the Kocaeli earthquake of 1999. The choice of these three earthquakes is motivated by the fact that they are characterised by substantially different frequency contents. Table 1 shows the maximum values of acceleration, $a_{\text {max,r }}$, duration, $T_{5-95}$, mean period, $T_{\mathrm{m}}$ (Rathje et al., 1998), and Arias intensity, $I_{\mathrm{a}}$. Fig. 1 shows the acceleration time histories and the Fourier spectra of the 
Table 1. Ground motion parameters of input earthquakes

\begin{tabular}{l|c|c|c|c}
\hline Record & $a_{\max , \mathrm{r}}: \boldsymbol{g}$ & $T_{5-95}: \mathrm{s}$ & $T_{\mathrm{m}}: \mathrm{s}$ & $I_{\mathrm{a}}: \mathrm{m} / \mathrm{s}$ \\
\hline Assisi & $0 \cdot 28$ & $4 \cdot 28$ & $0 \cdot 25$ & $0 \cdot 78$ \\
Tolmezzo & 0.35 & $4 \cdot 19$ & 0.40 & $0 \cdot 80$ \\
Arcelik & $0 \cdot 14$ & 7.23 & 1.09 & $0 \cdot 31$ \\
\hline
\end{tabular}

three signals. The recorded signals were baseline-corrected and low-pass-filtered at $15 \mathrm{~Hz}$ for compatibility with the dimension of the grid zones in the numerical domain; moreover, they were scaled at maximum accelerations ranging from $0.05 \mathrm{~g}$ to $0 \cdot 5 \mathrm{~g}$.

\section{Numerical model}

Two-dimensional, plane-strain, finite-difference analyses of a rectangular excavation of width $B=16 \mathrm{~m}$ and depth $h=4 \mathrm{~m}$, in a layer of dry sand with thickness $Z=16 \mathrm{~m}$, were carried out. The excavation was retained by a pair of cantilevered retaining walls.

Figure 2 shows the grid adopted in the numerical analyses, with an extension of $80 \mathrm{~m}$, consisting of a total of 4838 elements, with a minimum size of $0.33 \mathrm{~m}$ near the walls. Both the refinement of the mesh and the extension of the grid were chosen after a preliminary parametric study, in order that they did not influence the numerical results during either the static or dynamic stages.

The soil was modelled with a constant friction angle $\phi=35^{\circ}$, cohesion $c^{\prime}=0$, and density $\rho=2 \cdot 04 \mathrm{Mg} / \mathrm{m}^{3}$. A standard non-associated flow rule was used, with angle of dilatancy $\psi=0$. The small-strain shear modulus is given by

$$
\frac{G_{0}}{p_{\text {ref }}}=K_{\mathrm{G}}\left(\frac{p^{\prime}}{p_{\text {ref }}}\right)^{0 \cdot 5}
$$

where $p^{\prime}$ is the mean effective stress, $p_{\text {ref }}=100 \mathrm{kPa}$ is a reference pressure, and $K_{\mathrm{G}}$ is a stiffness multiplier, set equal to 1000 . Soil parameters $a=1.0, b=-0.6$ and $x_{0}=-1.5$ were used for the normalised secant shear modulus in equation (2), derived from the best fit of the modulus degradation curve proposed by Vucetic \& Dobry (1991) for cohesionless $(\mathrm{PI}=0)$ soils. Fig. 3 shows a comparison between the modulus decay curve and the equivalent damping ratio of the adopted model, and that suggested by Vucetic \& Dobry (1991).

The retaining walls were modelled as elastic beams connected to the grid nodes with elastic-perfectly plastic interfaces with a friction angle $\delta=20^{\circ}$. The bending stiffness of the walls was $E I=2.7 \times 10^{5} \mathrm{kN} \mathrm{m}^{2} / \mathrm{m}$, corresponding to that of a wall consisting of $0.6 \mathrm{~m}$ diameter and $0.7 \mathrm{~m}$ spacing bored piles. The walls can be considered, for all

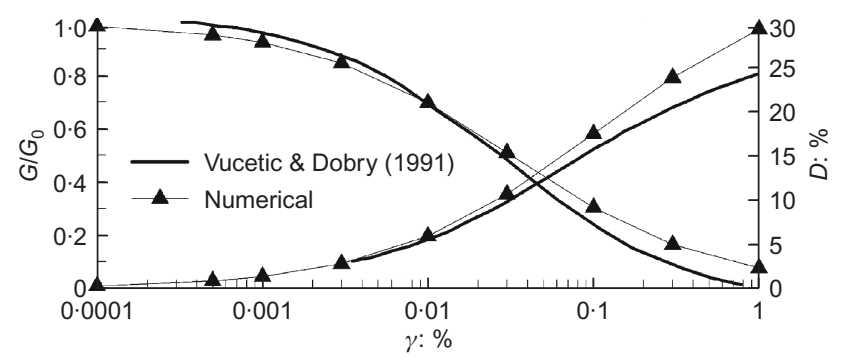

Fig. 3. Modulus decay and damping ratio curves (from Conti \& Viggiani, 2013)
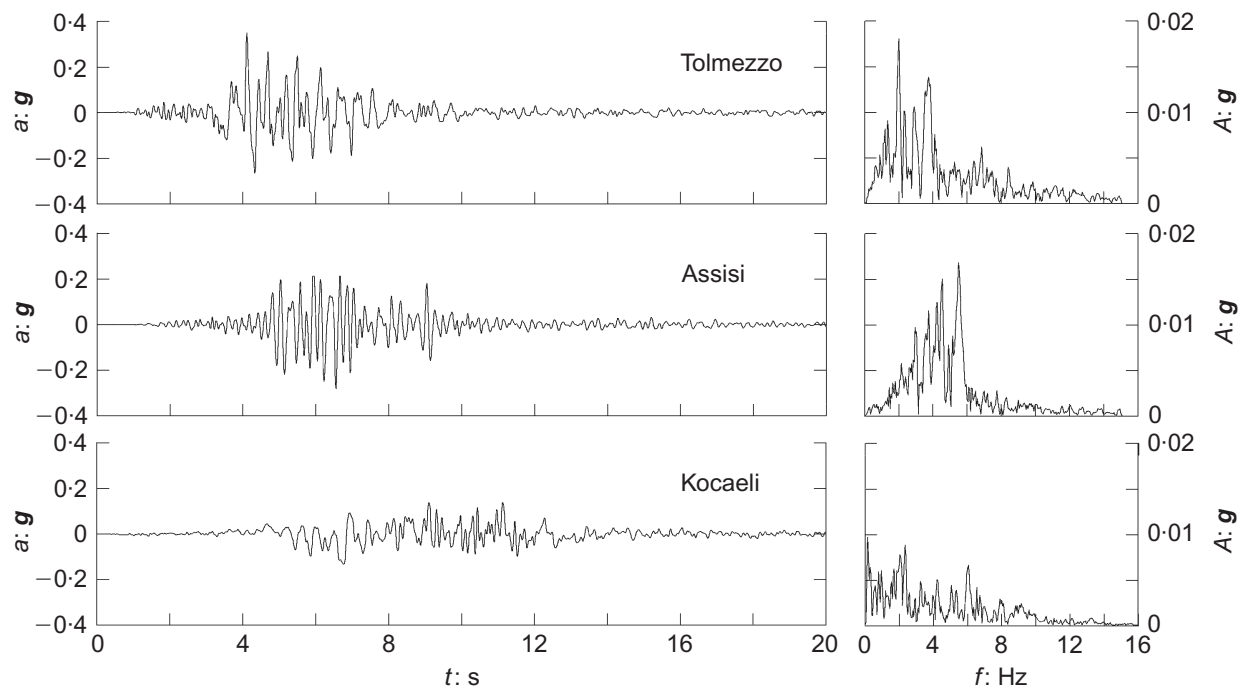

Fig. 1. Acceleration time histories and Fourier amplitude spectra of input earthquakes

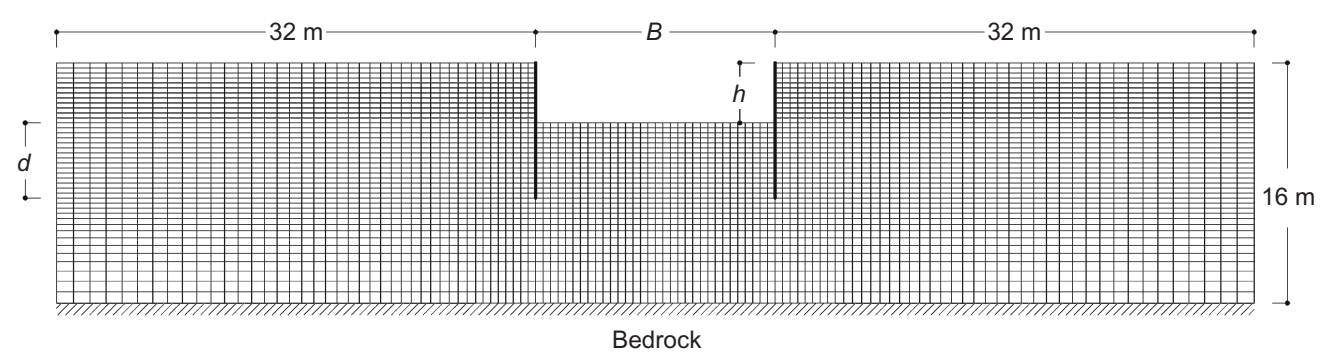

Fig. 2. Finite difference grid (from Conti \& Viggiani, 2013) 
practical purposes, as infinitely rigid (Callisto \& Soccodato, 2010).

The in situ stress state was prescribed in terms of the earth pressure coefficient at rest, $\sigma_{\mathrm{h}}^{\prime} / \sigma_{\mathrm{v}}^{\prime}=K_{0}(=1-\sin \phi)$. During the static stage, standard boundary conditions were applied to the model: that is, zero horizontal displacements along the lateral boundaries, and fixed nodes at the base of the grid. The excavation was carried out in four successive steps, chosen after a preliminary study in order to have the numerical results unaffected by the calculation sequence, during which the soil elements corresponding to $1 \mathrm{~m}$ of the excavated volume were removed. In this stage the shear modulus of the soil was set equal to $0 \cdot 3 G_{0}$, corresponding to a shear strain level of about $0 \cdot 1 \%$ (see Fig. 3), characteristic of the expected level of deformation during the excavation stage (Atkinson et al., 1993).

After the excavation, static constraints were removed from the boundaries. The selected acceleration-time histories were applied to the bottom nodes of the grid, together with a zero velocity condition in the vertical direction, thus simulating the presence of an infinitely rigid bedrock. Standard dynamic constraints (Zienkiewicz et al., 1988) were applied to the nodes on the lateral boundaries of the grid: that is, they were free to move in both the vertical and horizontal directions, while being tied to one another in order to enforce the same displacements of the two boundaries.
A time increment of $\Delta t=6.25 \times 10^{-7} \mathrm{~s}$ was adopted during the dynamic stage, in order to guarantee the stability of the explicit time integration scheme. Moreover, a small Rayleigh viscous damping (1\%) was adopted to remove the high-frequency noise deriving from the numerical integration, but not otherwise affecting the results of the analyses.

A total of 39 numerical analyses were carried out in this study, as reported in Table 2. Three different values were adopted for the embedded depth of the walls: $d=3 \mathrm{~m}$ (Nos 1 to 9 ), $d=4 \mathrm{~m}$ (Nos 10 to 21 ) and $d=5 \mathrm{~m}$ (Nos 22 to 36). For the analysis with $d=4 \mathrm{~m}$ and the Tolmezzo (T) record scaled to $0 \cdot 35 \mathrm{~g}$, the soil stiffness multiplier was halved and doubled (Nos 37 and 38), and a thickness of $Z=30 \mathrm{~m}$ was considered for the soil layer (No. 39).

\section{DISCUSSION OF RESULTS \\ Static stage}

At the end of the static stage, the soil around the excavation is approximately in limit equilibrium conditions, both in front and behind the walls. Fig. 4 shows, for the case $d=4 \mathrm{~m}$, the contour lines of: (a) the mobilised shear strength into the soil, defined as the ratio, $\tau / \tau_{\text {lim }}$ between the maximum shear stress and the corresponding available strength; and (b) the maximum shear strain (in \%) close to the left wall. Fig. 4(a) also shows the horizontal stress distribution in the soil elements at the contact with the wall,

Table 2. Summary of numerical analyses

\begin{tabular}{|c|c|c|c|c|c|c|}
\hline No. & Record & $a_{\mathrm{inp}}: \boldsymbol{g}$ & $d: \mathrm{m}$ & $Z: \mathrm{m}$ & $\left.E I: \mathrm{kN} \mathrm{m}^{2} / \mathrm{m}\right]$ & $K_{\mathrm{G}}$ \\
\hline 1 & Assisi & 0.05 & 3 & 16 & $2 \cdot 7 \cdot 10^{5}$ & 1000 \\
\hline 2 & Assisi & $0 \cdot 10$ & 3 & 16 & $2 \cdot 7 \cdot 10^{5}$ & 1000 \\
\hline 3 & Assisi & $0 \cdot 20$ & 3 & 16 & $2 \cdot 7 \cdot 10^{5}$ & 1000 \\
\hline 4 & Tolmezzo & 0.05 & 3 & 16 & $2 \cdot 7 \cdot 10^{5}$ & 1000 \\
\hline 5 & Tolmezzo & $0 \cdot 10$ & 3 & 16 & $2 \cdot 7 \cdot 10^{5}$ & 1000 \\
\hline 6 & Tolmezzo & $0 \cdot 20$ & 3 & 16 & $2 \cdot 7 \cdot 10^{5}$ & 1000 \\
\hline 7 & Arcelik & 0.05 & 3 & 16 & $2 \cdot 7 \cdot 10^{5}$ & 1000 \\
\hline 8 & Arcelik & $0 \cdot 10$ & 3 & 16 & $2 \cdot 7 \cdot 10^{5}$ & 1000 \\
\hline 9 & Arcelik & $0 \cdot 20$ & 3 & 16 & $2 \cdot 7 \cdot 10^{5}$ & 1000 \\
\hline 10 & Assisi & 0.05 & 4 & 16 & $2 \cdot 7 \cdot 10^{5}$ & 1000 \\
\hline 11 & Assisi & $0 \cdot 10$ & 4 & 16 & $2 \cdot 7 \cdot 10^{5}$ & 1000 \\
\hline 12 & Assisi & $0 \cdot 20$ & 4 & 16 & $2 \cdot 7 \cdot 10^{5}$ & 1000 \\
\hline 13 & Assisi & $0 \cdot 35$ & 4 & 16 & $2 \cdot 7 \cdot 10^{5}$ & 1000 \\
\hline 14 & Tolmezzo & 0.05 & 4 & 16 & $2 \cdot 7 \cdot 10^{5}$ & 1000 \\
\hline 15 & Tolmezzo & $0 \cdot 10$ & 4 & 16 & $2 \cdot 7 \cdot 10^{5}$ & 1000 \\
\hline 16 & Tolmezzo & $0 \cdot 20$ & 4 & 16 & $2 \cdot 7 \cdot 10^{5}$ & 1000 \\
\hline 17 & Tolmezzo & $0 \cdot 35$ & 4 & 16 & $2 \cdot 7 \cdot 10^{5}$ & 1000 \\
\hline 18 & Arcelik & 0.05 & 4 & 16 & $2 \cdot 7 \cdot 10^{5}$ & 1000 \\
\hline 19 & Arcelik & $0 \cdot 10$ & 4 & 16 & $2 \cdot 7 \cdot 10^{5}$ & 1000 \\
\hline 20 & Arcelik & $0 \cdot 20$ & 4 & 16 & $2 \cdot 7 \cdot 10^{5}$ & 1000 \\
\hline 21 & Arcelik & 0.35 & 4 & 16 & $2 \cdot 7 \cdot 10^{5}$ & 1000 \\
\hline 22 & Assisi & 0.05 & 5 & 16 & $2 \cdot 7 \cdot 10^{5}$ & 1000 \\
\hline 23 & Assisi & $0 \cdot 10$ & 5 & 16 & $2 \cdot 7 \cdot 10^{5}$ & 1000 \\
\hline 24 & Assisi & $0 \cdot 20$ & 5 & 16 & $2 \cdot 7 \cdot 10^{5}$ & 1000 \\
\hline 25 & Assisi & $0 \cdot 35$ & 5 & 16 & $2 \cdot 7 \cdot 10^{5}$ & 1000 \\
\hline 26 & Assisi & 0.50 & 5 & 16 & $2 \cdot 7 \cdot 10^{5}$ & 1000 \\
\hline 27 & Tolmezzo & 0.05 & 5 & 16 & $2 \cdot 7 \cdot 10^{5}$ & 1000 \\
\hline 28 & Tolmezzo & $0 \cdot 10$ & 5 & 16 & $2 \cdot 7 \cdot 10^{5}$ & 1000 \\
\hline 29 & Tolmezzo & $0 \cdot 20$ & 5 & 16 & $2 \cdot 7 \cdot 10^{5}$ & 1000 \\
\hline 30 & Tolmezzo & $0 \cdot 35$ & 5 & 16 & $2 \cdot 7 \cdot 10^{5}$ & 1000 \\
\hline 31 & Tolmezzo & $0 \cdot 50$ & 5 & 16 & $2 \cdot 7 \cdot 10^{5}$ & 1000 \\
\hline 32 & Arcelik & 0.05 & 5 & 16 & $2 \cdot 7 \cdot 10^{5}$ & 1000 \\
\hline 33 & Arcelik & $0 \cdot 10$ & 5 & 16 & $2 \cdot 7 \cdot 10^{5}$ & 1000 \\
\hline 34 & Arcelik & $0 \cdot 20$ & 5 & 16 & $2 \cdot 7 \cdot 10^{5}$ & 1000 \\
\hline 35 & Arcelik & 0.35 & 5 & 16 & $2 \cdot 7 \cdot 10^{5}$ & 1000 \\
\hline 36 & Arcelik & $0 \cdot 50$ & 5 & 16 & $2 \cdot 7 \cdot 10^{5}$ & 1000 \\
\hline 37 & Tolmezzo & 0.35 & 4 & 16 & $2 \cdot 7 \cdot 10^{5}$ & 500 \\
\hline 38 & Tolmezzo & $0 \cdot 35$ & 4 & 16 & $2 \cdot 7 \cdot 10^{5}$ & 2000 \\
\hline 39 & Tolmezzo & $0 \cdot 35$ & 4 & 30 & $2 \cdot 7 \cdot 10^{5}$ & 1000 \\
\hline
\end{tabular}




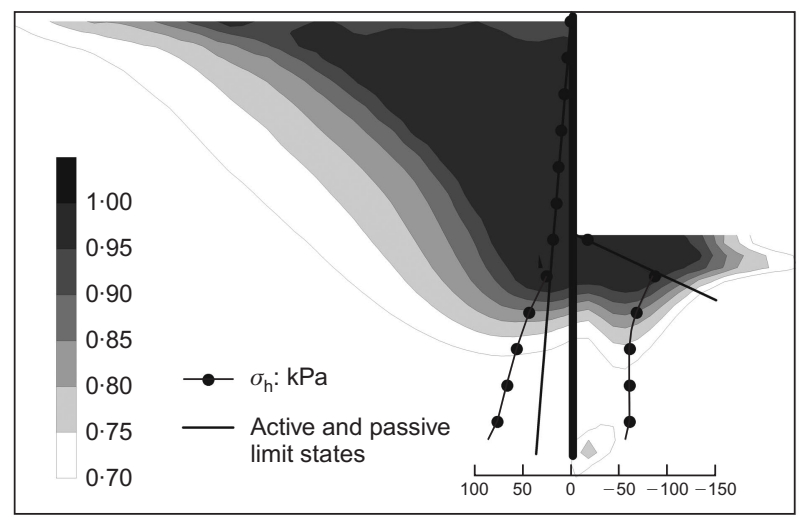

(a)

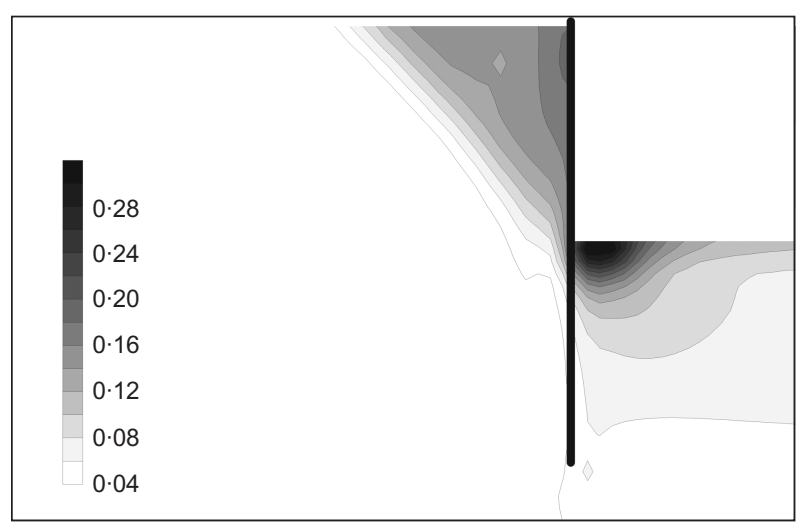

(b)

Fig. 4. Static stage $(d=4 \mathrm{~m})$. Contours of (a) mobilised shear strength, $\tau / \tau_{\text {lim }}$, and (b) maximum shear strain (\%) close to left wall

together with the theoretical values of the static active and passive pressure, computed with Lancellotta's closed-form solutions (Lancellotta, 2002). The soil behind the wall is in active limit state down to $5 \mathrm{~m}$ from the surface, whereas in front of the wall the passive resistance is fully mobilised only immediately below dredge level, the horizontal stresses being approximately constant in the remaining part of the embedded depth. The distribution of maximum shear strain into the soil is similar to that of the mobilised strength. Moreover, while a maximum shear strain of $0 \cdot 3 \%$ is mobilised just below dredge level, an average strain level of about $0 \cdot 1 \%$ is mobilised into the whole soil volume interacting with the wall during the static stage.

\section{Dynamic behaviour of retaining walls}

In this section, the dynamic behaviour of cantilevered retaining walls is discussed with reference to analyses Nos 14 to 17 , where the walls with $d=4 \mathrm{~m}$ are subjected to the Tolmezzo earthquake scaled to maximum input accelerations $a_{\text {inp }}=0 \cdot 05 g, 0 \cdot 10 g, 0 \cdot 20 g$ and $0 \cdot 35 g$.

Figure 5 shows, for the time instant when the acceleration behind the right wall reaches its maximum value

(a) the distribution of accelerations immediately behind and in front of the wall

(b) the contact horizontal stresses

(c) the bending moment distribution in the wall.

Figs 5(a) and 5(c) also show the critical acceleration of the wall and the corresponding bending moment distribution, computed using the Blum (1931) method, customarily adopted in the UK and other European countries, and described extensively in many works (e.g. Padfield \& Mair,
1984; Bica \& Clayton, 1989; King, 1995; Day, 1999), and a limit equilibrium method outlined herein. Fig. 5(d) shows the horizontal displacements of the wall computed at the end of each earthquake, while in Figs 5(e)-5(i) the computed contact stresses are plotted together with the dynamic active and passive limit values. The earth pressure coefficients, $k_{\mathrm{AE}}$ (Okabe, 1926; Mononobe \& Matsuo, 1929) and $k_{\mathrm{PE}}$ (Lancellotta, 2007), are computed using, at each depth, a pseudostatic acceleration equal to the acceleration resulting from the numerical analyses $\left(k_{\mathrm{h}}=a / g\right)$.

During the earthquakes, amplification phenomena around the excavation cause the surface accelerations behind the wall to be substantially larger than the maximum input accelerations, with amplification factors between 1.5 (No. 17) and 3.8 (No. 14). The distribution of accelerations into the soil is not uniform, owing to both amplification and phase shift between the top and the bottom of the wall; in the time instants when the acceleration reaches its maximum value, it varies almost linearly with depth behind the wall, at least in the retained part of the soil, while it is approximately constant below dredge level, and substantially lower than the maximum value at surface (Fig. 5(a)).

The inertia forces in the retained soil induce an increment of the contact stresses behind the wall, the soil being in active limit conditions. As a consequence, the wall rotates, mobilising the passive resistance of the soil below dredge level progressively, until the system reaches a new equilibrium configuration. The stronger the earthquake, the greater the depth down to which the passive resistance of the soil is fully mobilised (Figs 5(b), 5(f), 5(g), 5(h) and 5(i)). Both the increment of the contact stresses behind the wall and the lower position of the resultant of the pressure distribution in front of the wall cause a significant increase of the bending moments in the wall (Fig. 5(c)). At the end of the earthquakes, the horizontal displacements of the wall correspond to an approximately rigid rotation around a pivot point between $0 \cdot 8 d$ and $0 \cdot 9 d$ (Fig. $5(\mathrm{~d})$ ).

As far as the internal forces in the walls are concerned, the maximum bending moments may occur at instants of time when the acceleration at surface behind the wall is not maximum. As an example, Fig. 6 shows, for analysis No. 17 and for the time instants at which $a=a_{\max }(t=5.64 \mathrm{~s})$ and $M=M_{\max }(t=5.70 \mathrm{~s})$ : (a) the acceleration profile, (b, c) the earth pressure distribution, (d) the bending moment distribution, and $(\mathrm{e}, \mathrm{f})$ the contour lines of the ratio $\tau / \tau_{\mathrm{lim}}$. As already discussed, when the acceleration behind the wall reaches its maximum value $(t=5.64 \mathrm{~s})$, the retained soil is in active limit state conditions, at least down to $z=6 \mathrm{~m}$, while all the available resistance in front of the wall is mobilised down to $2 \mathrm{~m}$ from the excavation bottom. At this time instant, the occurrence of a soil wedge may be observed both behind (active) and in front (passive) of the wall (Fig. 6(e)). By contrast, for $t=5 \cdot 70 \mathrm{~s}$ the soil on both sides of the wall is far from limit conditions (Fig. 6(f)): that is, the horizontal stresses are higher than the corresponding active values on the retained side, while a constant fraction of the passive resistance is mobilised below dredge level (Fig. 6(c)). This stress distribution results in higher bending moments in the wall, even if the accelerations in the retained soil are about $20-30 \%$ lower than the values computed for $t=5.64 \mathrm{~s}$. The behaviour exhibited by the soil-wall system at this time instant would be hardly reproduced by a simplified limit equilibrium approach.

\section{Critical acceleration and limit equilibrium analysis}

The critical acceleration is computed with respect to an assumed failure mechanism, generally a rigid rotation about a point close to the toe for embedded cantilevered walls, 


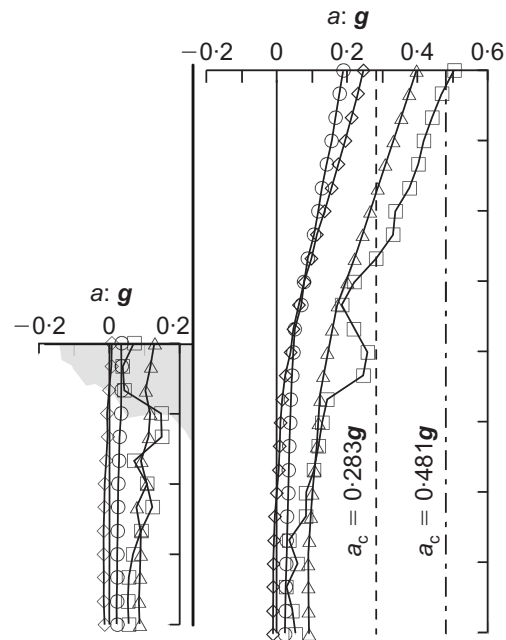

(a)

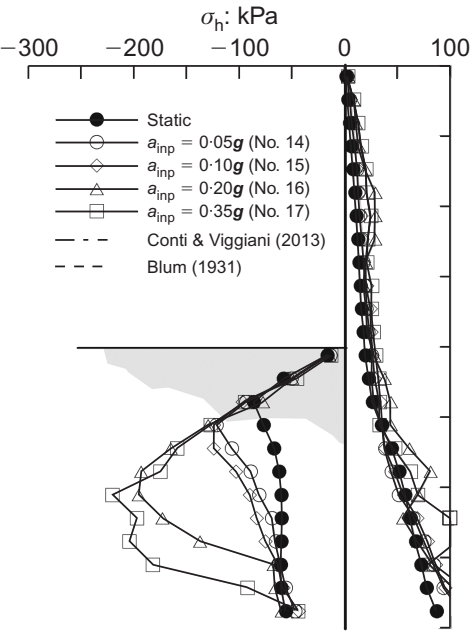

(b)

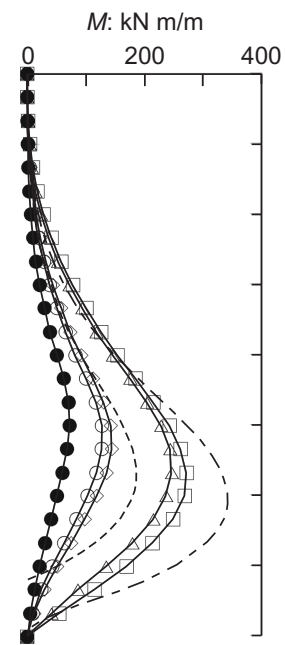

(c)

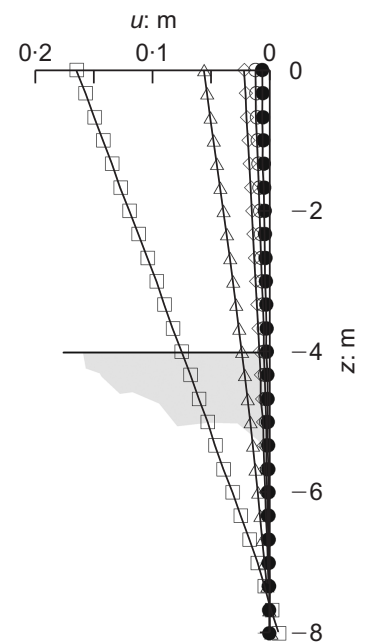

(d)

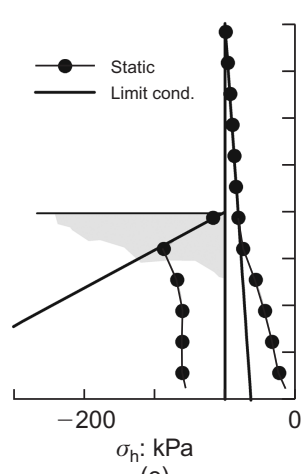

(e)

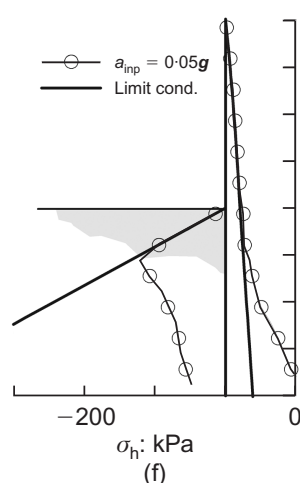

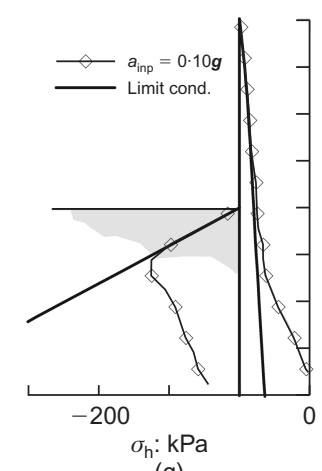

(g)

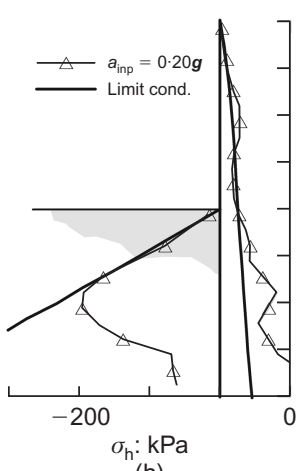

(h)

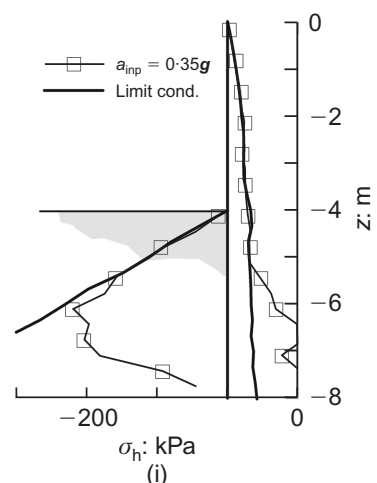

Fig. 5. Analyses Nos 14-17 (right wall): (a) distribution of accelerations behind and in front of wall; (b) and (e) to (i) contact horizontal stresses; (c) bending moment distribution for time instant when acceleration behind wall is maximum; (d) horizontal displacements of wall at end of each earthquake

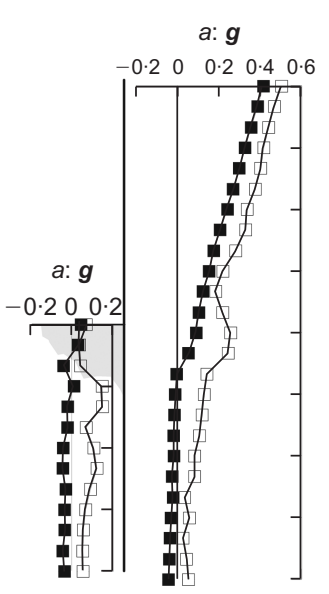

(a)

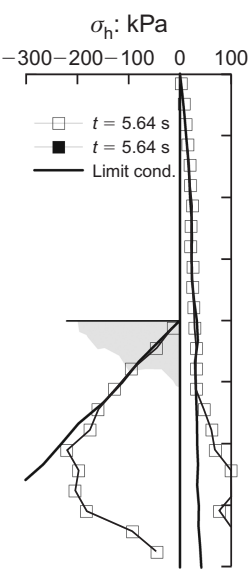

(b) $\sigma_{\mathrm{h}}: \mathrm{kPa}$

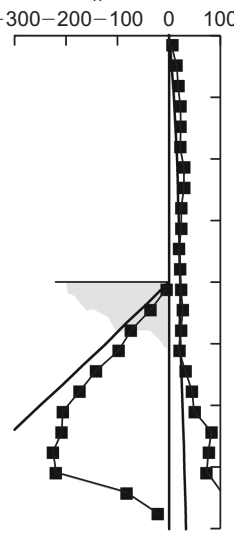

(c)

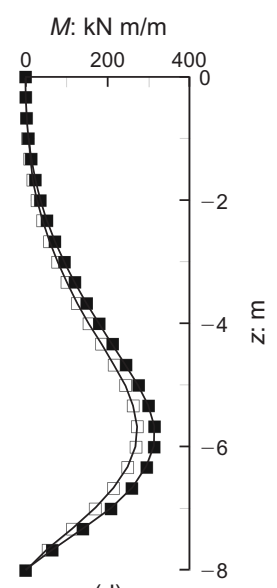

(d)

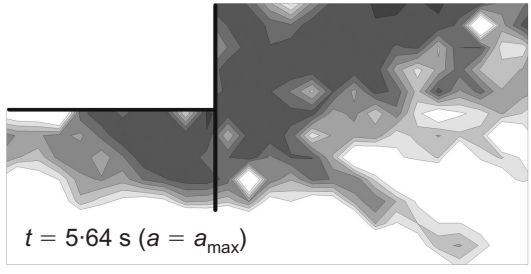

(e)

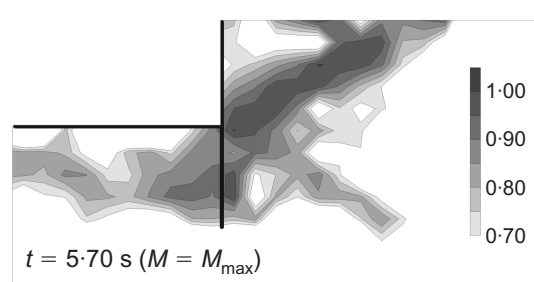

(f)

Fig. 6. Analysis No. 17 (right wall): (a) acceleration profile; (b), (c) earth pressure distribution; (d) bending moment distribution; (e), (f) contour lines of ratio $\tau / \tau_{\text {lim }}$, for time instants at which $a=a_{\max }$ and $M=M_{\max }$

and depends solely on the geometry of the system and the strength of the soil.

The results obtained by Callisto \& Soccodato (2010) show that the Blum method does not provide a reliable or conservative estimate of the critical acceleration, and hence of the maximum bending moment that the wall may ever experience during an earthquake. There are two main reasons for this. (a) In the Blum method, the same pseudo-static acceleration is assumed for the soil in front and behind the wall, whereas, in general, the acceleration below dredge level is only a small fraction of the maximum value on the retained side, and always lower than about $0 \cdot 1 \boldsymbol{g}$ (see Fig. 5(a)).

(b) The pivot point is taken to be at a depth of $0.8 d$ from dredge level, whereas it may be as deep as $0.9 d$ during strong earthquakes (see Fig. 5(d)). 
Moreover, for pseudo-static accelerations smaller than the critical value, the Blum method assumes a constant fraction of the soil passive resistance in front of the wall, whereas during real earthquakes this is progressively mobilised from the bottom of the excavation, depending on the amplitude of the acceleration applied (see Fig. 5(b)).

To take into account all these observations, a different pseudo-static distribution of contact stresses is used in this work (see Fig. 7). According to this approach (e.g. Conti \& Viggiani, 2013)

(a) the active earth pressure coefficient, $K_{\mathrm{AE}}$, is computed as a function of the assumed pseudo-static coefficient $k_{\mathrm{h}}$, while a static earth pressure coefficient, $K_{\mathrm{P}}$, is adopted for the passive resistance

(b) the strength of the soil in front of the wall is progressively mobilised down to a depth $\bar{d}$, as a function of $k_{\mathrm{h}}$

(c) the position of the pivot point, $d_{0}$, depends on $k_{\mathrm{h}}$, being about $0.9 d$ for $k_{\mathrm{h}}=k_{\mathrm{c}}$.

Using Fig. 7, the force equilibrium of the wall can be established by considering the forces acting on the righthand side $\left(F_{\mathrm{RHS}}\right)$ and on the left-hand side $\left(F_{\mathrm{LHS}}\right)$ of the wall, as follows.

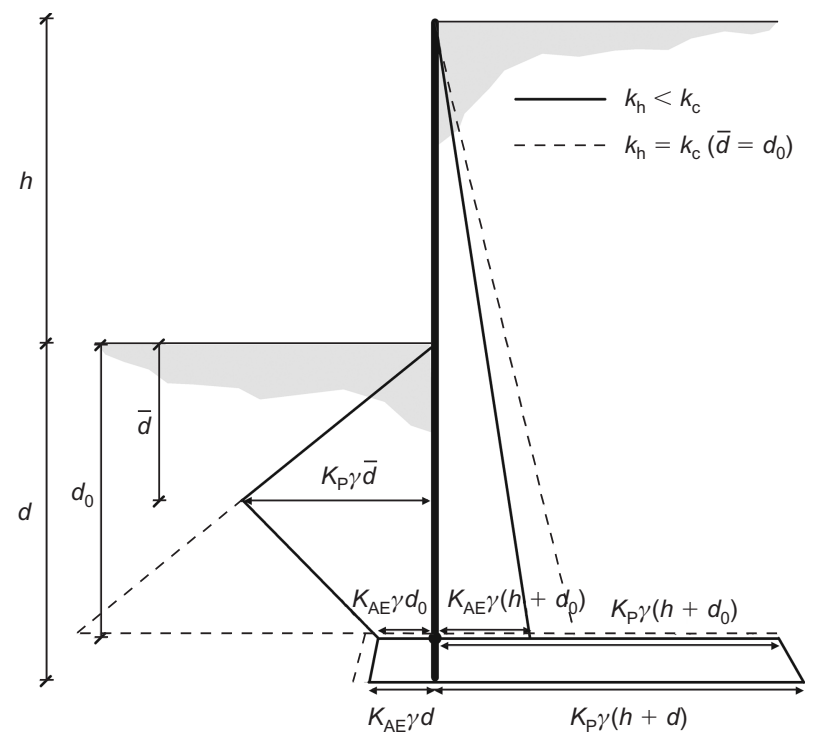

Fig. 7. Distribution of seismic earth pressures in proposed limit equilibrium method (from Conti \& Viggiani, 2013)

$$
\begin{aligned}
F_{\mathrm{RHS}}= & \frac{1}{2} \gamma K_{\mathrm{AE}}\left(h+d_{0}\right)^{2}+\frac{1}{2} \gamma K_{\mathrm{P}}\left(2 h+d+d_{0}\right)\left(d-d_{0}\right) \\
F_{\mathrm{LHS}}= & \frac{1}{2} \gamma K_{\mathrm{P}} \bar{d}^{2}+\frac{1}{2} \gamma\left(K_{\mathrm{P}} \bar{d}+K_{\mathrm{AE}} d_{0}\right)\left(d_{0}-\bar{d}\right) \\
& +\frac{1}{2} \gamma K_{\mathrm{AE}}\left(d+d_{0}\right)\left(d-d_{0}\right)
\end{aligned}
$$

Similarly, the moment equilibrium can be established by taking the moment about the toe of the wall, generated by the forces acting on the right-hand side $\left(M_{\mathrm{RHS}}\right)$ and on the left-hand side ( $\left.M_{\mathrm{LHS}}\right)$, to give

$$
\begin{aligned}
M_{\mathrm{RHS}}= & \frac{1}{2} \gamma K_{\mathrm{AE}}\left(h+d_{0}\right)^{2}\left[\frac{1}{3}\left(h+d_{0}\right)+\left(d-d_{0}\right)\right] \\
& +\frac{1}{6} \gamma K_{\mathrm{P}}\left(3 h+d+2 d_{0}\right)\left(d-d_{0}\right)^{2} \\
M_{\mathrm{LHS}}= & \frac{1}{2} \gamma K_{\mathrm{P}} \bar{d}^{2}\left(d-\frac{2}{3} \bar{d}\right) \\
& +\frac{1}{2} \gamma\left(K_{\mathrm{P}} \bar{d}+K_{\mathrm{AE}} d_{0}\right)\left(d_{0}-\bar{d}\right) \\
& \times\left[\left(\frac{d_{0}-\bar{d}}{3}\right)\left(\frac{K_{\mathrm{AE}} d_{0}+2 K_{\mathrm{P}} \bar{d}}{K_{\mathrm{AE}} d_{0}+K_{\mathrm{P}} \bar{d}}\right)+\left(d-d_{0}\right)\right] \\
& +\frac{1}{6} \gamma K_{\mathrm{AE}}\left(d-d_{0}\right)^{2}\left(d+2 d_{0}\right)
\end{aligned}
$$

By equating $F_{\mathrm{RHS}}=F_{\mathrm{LHS}}$ and $M_{\mathrm{RHS}}=M_{\mathrm{LHS}}$ one obtains a system of two equations in the two unknowns $\bar{d}$ and $d_{0}$.

Figure 8 shows the maximum bending moment on the walls computed from all the numerical analyses, as a function of the surface acceleration behind the walls at the same time instant; analyses 37 to 39 are those carried out using different values of the small-strain stiffness of the soil, $G_{0}$, and of the total height of the wall, $H$. Fig. 8 also shows the limit equilibrium maximum bending moment, as a function of $k_{\mathrm{h}}$, computed according to both the Blum method and the proposed method. For completeness, the results obtained with the earth pressure distribution adopted customarily in the USA, and described in detail by Bowles (1988), King (1995) and Day (1999), are also reported in the figure. Internal forces on the walls increase as a function of the applied acceleration, until the critical acceleration is reached. As an example, for $d=3 \mathrm{~m}$ and $d=4 \mathrm{~m}$ the numerical maximum bending moments reach a plateau for accelerations greater than $0 \cdot 3 \mathrm{~g}$ and $0.48 \mathrm{~g}$ respectively, their maximum values being about $185 \mathrm{kN} \mathrm{m} / \mathrm{m}$ and $330 \mathrm{kN} \mathrm{m} / \mathrm{m}$ respectively. In this case, critical accelerations predicted by the proposed approach, and the corresponding maximum

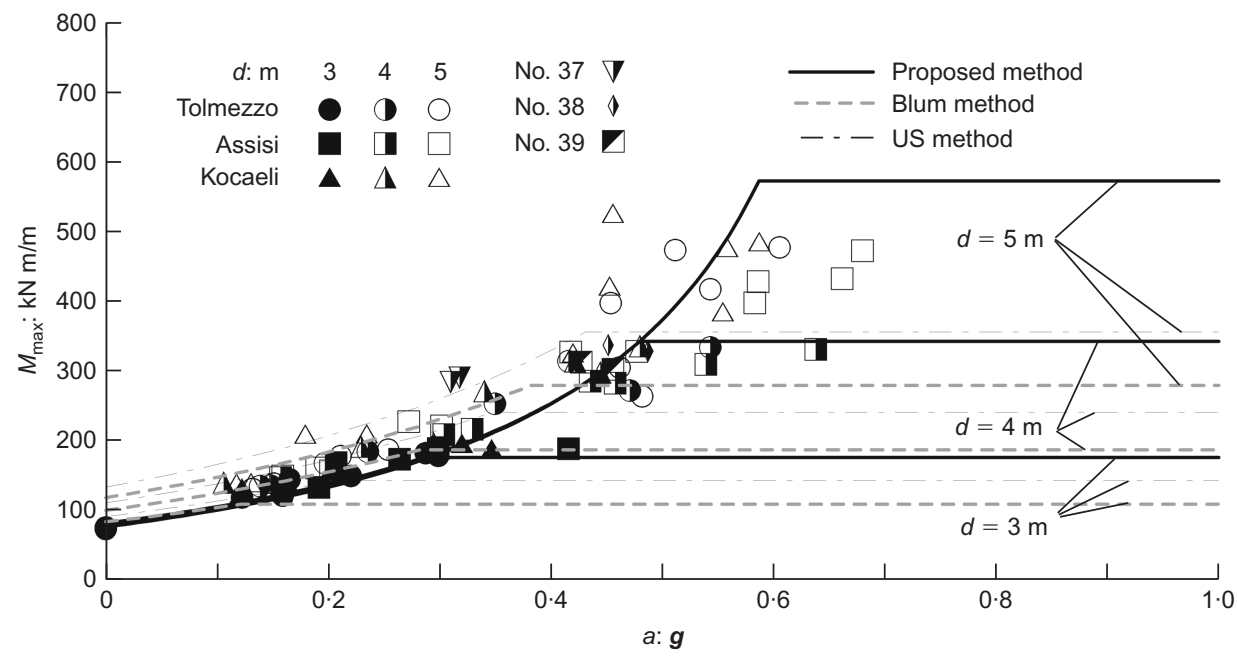

Fig. 8. Maximum bending moment as a function of surface acceleration behind walls computed at the same time instant, and limit equilibrium results 
bending moments, are $a_{\mathrm{c}}=0 \cdot 29 \mathrm{~g}$ and $M_{\mathrm{c}}=175 \mathrm{kN} \mathrm{m} / \mathrm{m}$ for $d=3 \mathrm{~m}$, and $a_{\mathrm{c}}=0.48 \mathrm{~g}$ and $M_{\mathrm{c}}=342 \mathrm{kN} \mathrm{m} / \mathrm{m}$ for $d=4 \mathrm{~m}$, showing a very good agreement with the numerical data. A more dispersed trend is observed for $d=5 \mathrm{~m}$, where the maximum bending moments do not seem to reach a limit value for the earthquakes applied. The fact that the pseudostatic approach does not always predict the numerical observations satisfactorily, at least for $a<a_{\mathrm{c}}$, is due mainly to the fact that the soil around the excavation is not always in limit conditions when bending moments on the walls attain their maximum value, as already discussed. However, the proposed method provides an accurate estimate of the maximum (critical) internal forces that the walls may ever attain during an earthquake, whereas the Blum and US methods always underpredict the maximum bending moments substantially. It is worth noting that the critical acceleration, and hence the maximum bending moment, increase with $d$ - that is, the longer (and safer) the wall, the larger the bending moment it has to sustain under a strong earthquake.

\section{Newmark analysis}

The horizontal displacement of the top of the wall is an important parameter in performance-based seismic design, as the settlements of the ground surface behind retaining structures, and hence the potential damage to adjacent buildings, are related to the horizontal displacements of the wall (Mana \& Clough, 1981; Hsieh \& Ou, 1998; Kung et al., 2007; Wang et al., 2010). Fig. 9 shows the final horizontal displacements of the top of the wall, $u$, normalised by the total height of the wall, $H$, as a function of the ratio $a_{\mathrm{c}} / a_{\max }$ between the critical acceleration computed with the pseudostatic approach outlined above, and the maximum acceleration behind the walls. As expected, the displacements of the walls increase as the intensity of the applied earthquake increases. However, as shown by Conti et al. (2012) on the basis of centrifuge tests, the walls can accumulate significant displacements $(u / H>1-2 \%)$, even for accelerations lower than the critical one, and hence before the available soil passive resistance is fully mobilised in front of the wall. These displacements cannot be computed by a conventional Newmark (1965) analysis, that is, assuming a yield acceleration equal to the critical value provided by the limit equilibrium analysis. Following the procedure adopted by Conti et al. (2012) for the interpretation of centrifuge dynamic tests, a Newmark calculation was carried out for each analysis, in which the yield acceleration, $a_{\mathrm{c}_{\mathrm{N}}}$, was found by trial and error to match computed and numerical displacements at the end of each earthquake. As an example, Fig. 10 shows, for analysis No. 17, (a) the acceleration time histories computed at the soil surface, and (b) the horizontal displacements of the top of the right wall. The yield acceleration, $a_{\mathrm{c}_{\mathrm{N}}}$, required to match the computed final displacement is only a

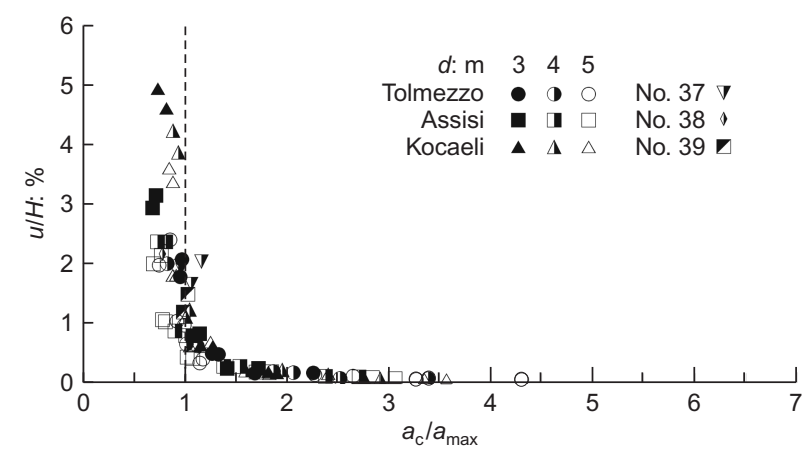

Fig. 9. Final normalised horizontal displacements of top of walls, as a function of the ratio $a_{\mathrm{c}} / a_{\max }$

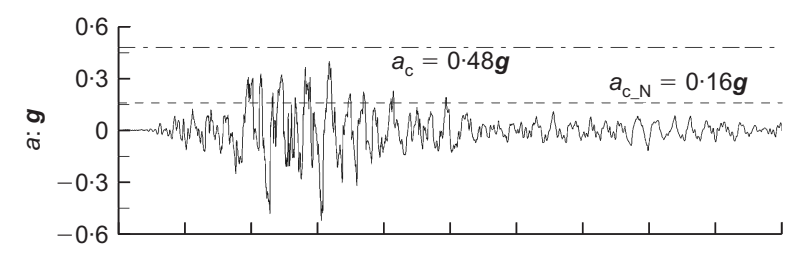

(a)

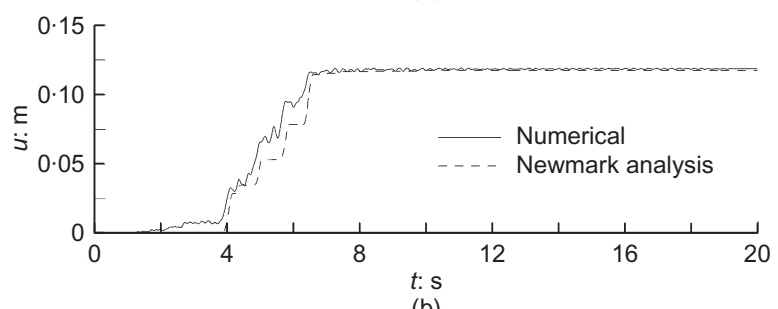

(b)

Fig. 10. Analysis No. 17: (a) acceleration time histories computed at soil surface; (b) horizontal displacements of top of right wall. Comparison between results from numerical and Newmark analysis

fraction of the critical acceleration $a_{\mathrm{c}}$ that corresponds to the complete mobilisation of the soil passive strength; in other words, had the Newmark analysis been carried out using $a_{\mathrm{c}}$, the displacements of the wall would have been zero.

Figure 11 shows the computed values of $a_{\mathrm{c}_{\mathrm{N}}}$ as a function of the maximum acceleration $a_{\max }$, both normalised by the limit equilibrium value of the critical acceleration, $a_{\mathrm{c}}$. Data from centrifuge tests (Conti et al., 2012) have been also included in the same figure for comparison. Both numerical and experimental data indicate that $a_{\mathrm{c}_{\mathrm{N}}} / a_{\mathrm{c}}$ increases with the maximum acceleration applied, up to about $a_{\max } / a_{\mathrm{c}}=1 \cdot 0$, and it is then approximately constant, and equal to about $40 \%$. This result is not significantly affected by the characteristics of the applied earthquakes, such as frequency content, duration or Arias intensity.

\section{GUIDELINES FOR DESIGN}

The seismic design of embedded cantilevered retaining walls for a given value of the maximum acceleration expected at the site, $a_{\text {max,1D }}$, must address the issues both of: (a) the geotechnical design of the wall, that is, the calculation of a depth of embedment such that the permanent horizontal displacement of the top of the wall at the end of the earthquake, taken as an indicator of the performance of the retaining structure, is less than or equal to an admissible value; and (b) the structural design of the wall, that is, the definition of the structural section needed to sustain the maximum internal forces experienced by the wall during the earthquake. In the following, the authors try to provide guidelines for the seismic design of retaining structures using simplified methods, in the light of the results presented so far.

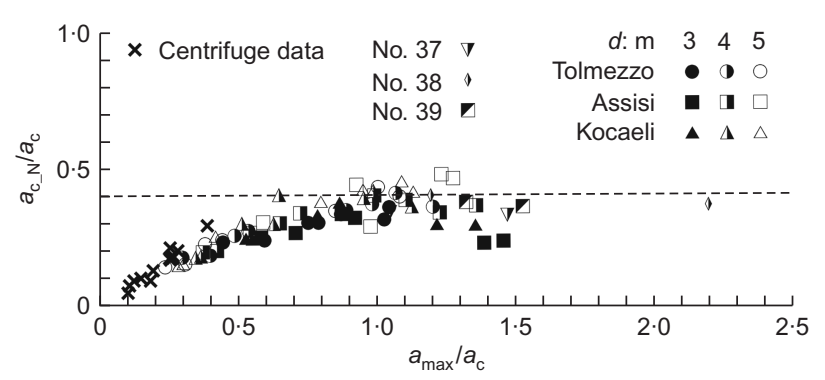

Fig. 11. Computed values of $a_{c_{N}}$ as a function of maximum acceleration $a_{\text {max }}$, both normalised by limit equilibrium value of critical acceleration, $a_{\mathrm{c}}$ 


\section{Geotechnical design}

Figure 12 is similar to Fig. 9, but this time the final normalised displacements of the top of the wall, $u / H$, are plotted as a function of the ratio $a_{\mathrm{c}} / a_{\max , 1 \mathrm{D}}$, where $a_{\max , 1 \mathrm{D}}$ is the maximum acceleration at the surface (free field) computed from one-dimensional site response analyses using FLAC. Similar to Richards \& Elms (1979), the data were interpolated with a power function, which is plotted in Fig. 12 together with the $98 \%$ confidence intervals.

For each design earthquake motion, corresponding to which an allowable displacement is prescribed, the upperbound curve in Fig. 12 can be used to obtain the ratio $\beta=a_{\mathrm{c}} / a_{\max , 1 \mathrm{D}}$ and then the required critical acceleration. Clearly, the effective value of the critical acceleration for the wall must be the maximum among all the design earthquakes. Once $a_{\mathrm{c}}$ is known, the depth of embedment of the wall can be computed iteratively using the proposed limit equilibrium approach, with $k_{\mathrm{h}}=a_{\mathrm{h}} / \boldsymbol{g}=a_{\mathrm{c}} / \boldsymbol{g}$, until the (critical) condition $\bar{d}=d_{0}$ is satisfied. Any introduction of a safety factor at this stage would ensure that the displacements experienced by the wall are less than the admissible value.

Allowable displacements less than about $3 \%$ of $H$ would result in a ratio $a_{\mathrm{c}} / a_{\max , 1 \mathrm{D}}>1$ : that is, the wall should be designed to have a critical acceleration larger than the maximum acceleration expected at the site (i.e. using an equivalent acceleration that is larger than the maximum free-field acceleration). This is completely different from the performance-based design of gravity retaining walls, as they will experience permanent displacements only if their critical acceleration is lower than the maximum acceleration of the design earthquake $(\beta<1)$. As already discussed, this difference arises from the fact that embedded cantilevered walls begin to rotate for accelerations lower than the critical value.

\section{Structural design}

For the structural design of retaining walls, the maximum bending moment, $M_{\max }$, must be computed under a realistic distribution of contact stresses between the soil and the structure. Its value is closely related to the maximum acceleration at surface behind the walls, $a_{\max }$. As already observed by Callisto \& Soccodato (2010) values of $a_{\max }$ can only be computed taking into account soil-structure interaction effects, as the maximum accelerations behind retaining structures depend not only on the dynamic properties and thickness of the soil layer, but also on a number of factors, such as the geometry of the excavation, the bending stiffness of the wall and the embedded depth, which all affect the natural frequency of the soil-wall system. As an example, Fig. 13 shows the ratio $a_{\max } / a_{\max , 1 \mathrm{D}}$ between the maximum acceleration computed behind the walls, $a_{\max }$, and the maximum free-field acceleration obtained by one-dimensional

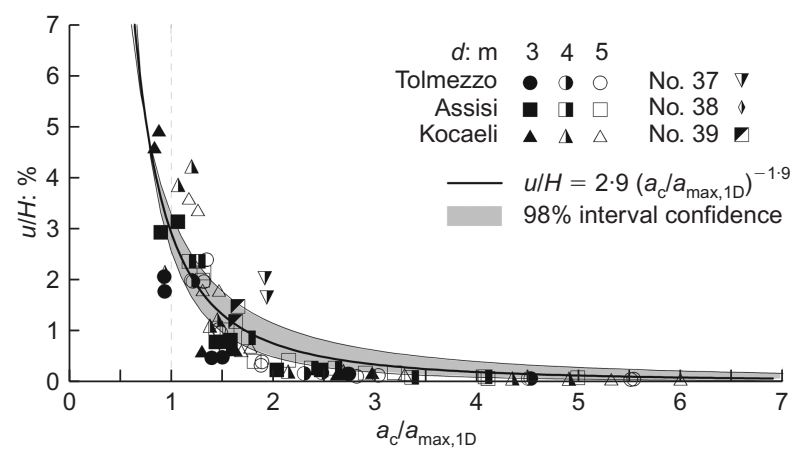

Fig. 12. Final normalised horizontal displacements of top of walls, as a function of the ratio $a_{\mathrm{c}} / a_{\mathrm{max}, 1 \mathrm{D}}$

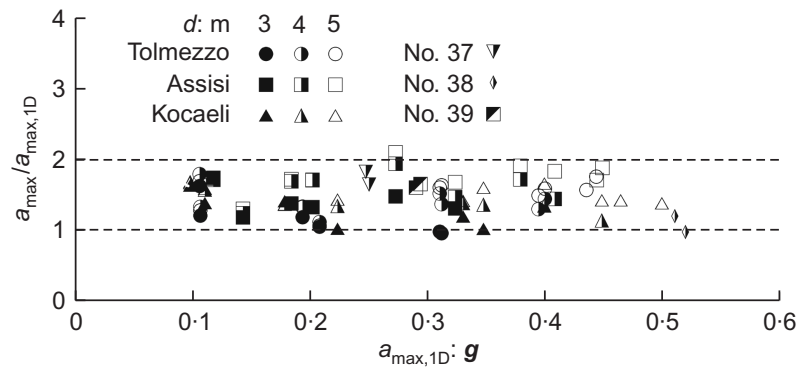

Fig. 13. Ratio $a_{\max } / a_{\max , 1 \mathrm{D}}$ between maximum acceleration computed behind walls and maximum free-field acceleration obtained by one-dimensional seismic response analyses, as a function of $a_{\max , 1 \mathrm{D}}$

seismic response analyses, $a_{\max , 1 \mathrm{D}}$, as a function of $a_{\max , 1 \mathrm{D}}$. Two-dimensional phenomena clearly induce a stronger (further) amplification than that merely associated with onedimensional shear wave propagation, but, at least for the range of geometrical and mechanical factors considered in this parametric study, the ratio $a_{\max } / a_{\max , 1 \mathrm{D}}$ is always less than about 2 , and not significantly affected by the ground motion parameters of the earthquakes applied.

Figure 14 shows the numerical values of the maximum bending moment, $M_{\max }$, normalised by the maximum static bending moment, $M_{\text {stat }}$, as a function of $a_{\max } / a_{\mathrm{c}}$, together with the pseudo-static bending moments computed according to the proposed method. The figure shows a good agreement between numerical and pseudo-static results, for all the applied earthquakes. Moreover, limit equilibrium clearly provides an accurate estimate of the maximum (critical) internal forces that a wall with a given value of the critical acceleration may ever attain during an earthquake, which is therefore always a conservative value for the structural design of the wall. For this purpose, pseudo-static bending moments can then be computed using the earth pressure distribution outlined in this work, with a pseudo-static coefficient $k_{\mathrm{h}}=a_{\max } / g$. A conservative value of $a_{\max }$ would be $a_{\max }=2 a_{\max , 1 \mathrm{D}}$.

\section{CONCLUSIONS}

This paper has addressed the issue of the seismic design of embedded cantilevered retaining walls, in the light of the results obtained from an extensive set of numerical analyses of a pair of cantilevered walls in dry sand, subjected to real earthquakes scaled at different values of the maximum acceleration. The results of the analyses confirm that embedded cantilevered retaining walls experience permanent displacements even before the acceleration reaches its critical value, corresponding to full mobilisation of the shear strength of the soil.

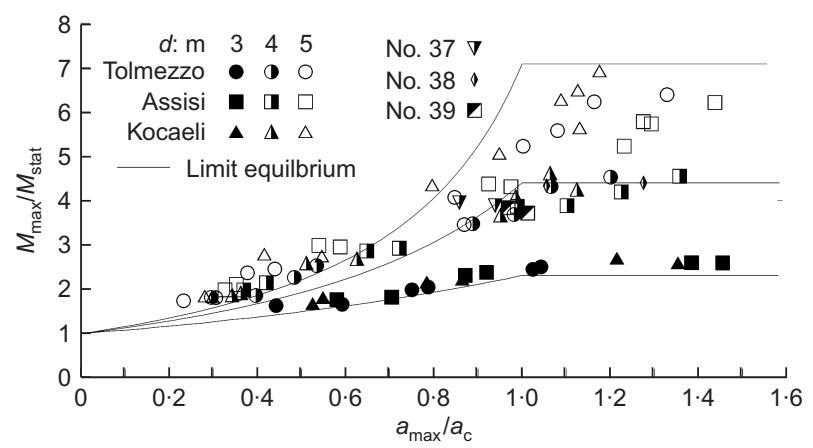

Fig. 14. Maximum normalised bending moments, as a function of $a_{\max } / a_{\mathrm{c}}:$ numerical and limit equilibrium results 
For the geotechnical design of the wall, if the permanent displacement at the end of the earthquake is taken as a performance indicator, the choice of the equivalent acceleration to be used in the pseudo-static calculations should be related to the maximum displacements that the structure can sustain, with respect to different levels of design earthquake motion. In this case, the relationship between the final displacements of the top of the wall and the ratio $a_{\mathrm{c}} / a_{\max , 1 \mathrm{D}}$ (Fig. 12) can be used to obtain the equivalent acceleration, for any given allowable displacement of the wall. This can be expressed as $a_{\mathrm{h}}=\beta a_{\max , 1 \mathrm{D}}$, where $\beta\left(=a_{\mathrm{c}} / a_{\mathrm{max}, 1 \mathrm{D})}\right.$ can be larger than 1 .

For the structural design of the wall, the maximum bending moments can be computed using a realistic distribution of contact stresses, such as that proposed in this work, and a conservative value of the pseudo-static acceleration: $k_{\mathrm{h}}=a_{\max } / \boldsymbol{g}=2 a_{\max , 1 \mathrm{D}}$.

The data discussed in the paper refer only to cantilevered walls in dry sand; further research is required to clarify the role of the presence of the pore water, for either saturated or unsaturated soils.

\section{ACKNOWLEDGEMENTS}

The work presented in this paper was developed with the financial support of the Italian Department of Civil Protection within the ReLUIS research project.

\section{NOTATION}

$a, b, x_{0}$ constants of the hysteretic model

$d$ depth of embedment

$d_{0}$ depth of pivot point

$\bar{d}$ depth of full mobilisation of passive soil pressure

$G_{\mathrm{S}}$ secant shear modulus

$G_{0}$ small-strain shear modulus

$h$ excavation depth

$K_{\mathrm{AE}}$ dynamic active earth pressure coefficient

$K_{\mathrm{G}} \quad$ stiffness multiplier

$K_{\mathrm{P}} \quad$ static passive earth pressure coefficient

$M_{\mathrm{S}}$ normalised secant shear modulus

$p^{\prime}$ mean effective stress

$p_{\text {ref }}$ reference pressure

$\gamma$ shear strain; soil unit weight

$\tau$ shear stress

\section{REFERENCES}

Atik, L. A. \& Sitar, N. (2010). Seismic earth pressures on cantilever retaining structures. J. Geotech. Geoenviron. Engng 136, No. 10, $1324-1333$.

Atkinson, J. H., Coop, M. R., Stallebrass, S. E. \& Viggiani, G. (1993). Measurement of stiffness of soils and weak rocks in laboratory tests. Proceedings of the 25th annual conference of the Engineering Group of the Geological Society, Leeds, UK, pp. $21-27$.

Basha, B. M. \& Babu, L. S. B. (2010). Seismic rotational displacements of gravity walls by pseudodynamic method with curved rupture surface. Int. J. Geomech. 10, No. 3, 93-105.

Bica, A. V. D. \& Clayton, C. R. I. (1989). Limit equilibrium design methods for free embedded cantilever wall in granular materials. Proc. Inst. Civ. Engrs, Part 1 86, No. 5, 879-898.

Blum, H. (1931). Einspannungsverhältnisse bei Bohlkwerken. Berlin, Germany: Wil. Ernst und Sohn (in German).

Bowles, J. E. (1988). Foundation analysis and design, 4th edn. New York, NY, USA: McGraw-Hill.

Callisto, L. \& Soccodato, F. M. (2007). Seismic analysis of an embedded retaining structure in coarse-grained soils. Proceedings of the 4th international conference on earthquake geotechnical engineering, Thessaloniki, Greece, paper no. 1197.

Callisto, L. \& Soccodato, F. M. (2010). Seismic design of flexible cantilevered retaining walls. J. Geotech. Geoenviron. Engng 136, No. 2, 344-354.
Callisto, L., Soccodato, F. M. \& Conti, R. (2008). Analysis of the seismic behaviour of propped retaining structures. In Geotechnical earthquake engineering and soil dynamic IV (eds D. Zeng, M. T. Manzari and D. R. Hiltunen), GSP 181, pp. 1-10. Reston, VA, USA: ASCE.

CEN (2003). EN 1998-5:2003: Eurocode 8: Design of structures for earthquake resistance - Part 5: Foundations, retaining structures and geotechnical aspects. Brussels, Belgium: European Committee for Standardization.

Cilingir, U., Haigh, S. K., Madabhushi, S. P. G. \& Zeng, X. (2011). Seismic behaviour of anchored quay walls with dry backfill. Geomech. Geoengng 6, No. 3, 227-235.

Conti, R. \& Viggiani, G. M. B. (2013). A new limit equilibrium method for the pseudostatic design of embedded cantilevered retaining walls. Soil Dynam. Earthquake Engng 50, 143-150.

Conti, R., Madabhushi, S. P. G. \& Viggiani, G. M. B. (2012). On the behaviour of flexible retaining walls under seismic actions. Géotechnique 62, No. 12, 1081-1094, http://dx.doi.org/10.1680/ geot.11.P.029.

Day, R. A. (1999). Net pressure analysis of cantilever sheet pile walls. Géotechnique 49, No. 2, 231-245, http://dx.doi.org/ 10.1680/geot.1999.49.2.231.

Evangelista, A., Scotto di Santolo, A. \& Simonelli, A. L. (2010). Evaluation of pseudostatic active earth pressure coefficient of cantilever retaining walls. Soil Dynam. Earthquake Engng 30, No. 11, 1119-1128.

Fang, Y. S., Yang, Y. C. \& Chen, T. J. (2003). Retaining walls damaged in the Chi-Chi earthquake. Can. Geotech. J. 40, No. 6, $1142-1153$.

Gazetas, G., Psarropoulos, P. N., Anastasopoulos, I. \& Gerolymos, N. (2004). Seismic behaviour of flexible retaining systems subjected to short-duration moderately strong excitation. Soil Dynam. Earthquake Engng 24, No. 7, 537-550.

Hsieh, P. G. \& Ou, C. Y. (1998). Shape of ground surface settlement profiles caused by excavation. Can. Geotech. J. 35, No. 6, 1004-1017.

Huang, C. C., Wu, S. H. \& Wu, H. J. (2009). Seismic displacement criterion for soil retaining walls based on soil strength mobilization. J. Geotech. Geoenviron. Engng 135, No. 1, 74-83.

Iai, S. \& Kameoka, T. (1993). Finite element analysis of earthquake induced damage to anchored sheet pile quay walls. Soils Found. 33, No. 1, 71-91.

Itasca (2005). FLAC Fast Lagrangian Analysis of Continua. v. 5.0. User's Manual. Minneapolis, MN, USA: Itasca Consulting Group.

Kim, W. C., Park, D. \& Kim, B. (2010). Development of a generalised formula for dynamic active earth pressure. Géotechnique 60, No. 9, 723-727, http://dx.doi.org/10.1680/geot.09.T.001.

King, G. J. W. (1995). Analysis of cantilever sheet-pile walls in cohesionless soil. J. Geotech. Engng Div., ASCE 121, No. 9, 629-635.

Kontoe, S., Zdravkovic, L., Menkiti, C. O. \& Potts, D. M. (2012). Seismic response and interaction of complex soil retaining systems. Comput. Geotech. 39, January, 17-26.

Koseki, J., Koda, M., Matsuo, S., Takasaki, H. \& Fujiwara, T. (2012). Damage to railway earth structures and foundations caused by the 2011 off the Pacific Coast of Tohoku Earthquake. Soils Found. 52, No. 5, 872-889.

Kung, G. T. C., Juang, H., Hsiao, E. C. L. \& Hashash, Y. M. A. (2007). Simplified model for wall deflection and ground-surface settlement caused by braced excavation in clays. J. Geotech. Geoenviron. Engng 133, No. 6, 731-747.

Lancellotta, R. (2002). Analytical solution of passive earth pressure. Géotechnique 52, No. 8, 617-619, http://dx.doi.org/10.1680/ geot.2002.52.8.617.

Lancellotta, R. (2007). Lower-bound approach for seismic passive earth resistance. Géotechnique 57, No. 3, 319-321, http:// dx.doi.org/10.1680/geot.2007.57.3.319.

Ling, H. I. (2001). Recent applications of sliding block theory to geotechnical design. Soil Dynam. Earthquake Engng 21, No. 3, 189-197.

Madabhushi, S. P. G. \& Zeng, X. (2006). Seismic response of flexible cantilever retaining walls with dry backfill. Geomech. Geoengng 1, No. 4, 275-289.

Madabhushi, S. P. G. \& Zeng, X. (2007). Simulating seismic 
response of cantilever retaining walls. J. Geotech. Geoenviron. Engng 133, No. 5, 539-549.

Mana, A. I. \& Clough, G. W. (1981). Prediction of movements for braced cuts in clay. J. Geotech. Engng Div., ASCE 107, No. 6, $759-777$.

Masing, G. (1926). Eigenspannungen und Verfertigung bim Messing. Proceedings of the 2nd international congress on applied mechanics, Zurich, Switzerland, pp. 332-335.

Mononobe, N. \& Matsuo, H. (1929). On the determination of earth pressure during earthquake. Proceedings of the 2nd world engineering conference, Tokyo, Japan, vol. 9, pp. 177-185.

Mylonakis, G., Kloukinas, P. \& Papantonopoulos, C. (2007). An alternative to the Mononobe-Okabe equations for seismic earth pressures. Soil Dynam. Earthquake Engng 27, No. 10, 957-969.

Neelakantan, G., Budhu, M. \& Richards, R. (1992). Balanced seismic design of anchored retaining walls. J. Geotech. Engng 118, No. 6, 873-888.

Newmark, N. M. (1965). Effects of earthquakes on dams and embankments. Géotechnique 15, No. 2, 139-160, http:// dx.doi.org/10.1680/geot.1965.15.2.139.

NTC (2008). Norme Tecniche per le Costruzioni. Gazzetta Ufficiale della Repubblica Italiana 04/12/2008, Supplemento Ordinario 29, No. 30 (in Italian).

Okabe, S. (1926). General theory of earth pressure and seismic stability of retaining wall and dam. J. Jpn. Soc. Civ. Engng 10, No. 6, 1277-1288.

Osman, A. S. \& Bolton, M. D. (2004). A new design method for retaining walls in clay. Can. Geotech. J. 41, No. 3, 453-469.

PIANC (2001). Seismic design guidelines for port structures (Working Group N34 of the Maritime Navigation Commission, International Navigation Association). Rotterdam, the Netherlands: Balkema.

Padfield, C. J. \& Mair, R. J. (1984). Design of retaining walls embedded in stiff clay, CIRIA Report R104. London, UK: Construction Industry Research and Information Association.

Powrie, W. (1996). Limit equilibrium analysis of embedded retaining walls. Géotechnique 46, No. 4, 709-723, http://dx.doi.org/ 10.1680/geot.1996.46.4.709.

Rathje, E. M., Abrahamson, N. A. \& Bray, J. D. (1998). Simplified frequency content estimates of earthquake ground motions. J. Geotech. Geoenviron. Engng 124, No. 2, 150-159.

Richards, R. \& Elms, D. G. (1979). Seismic behavior of gravity retaining walls. J. Geotech. Engng Div., ASCE 105, No. 4, 449464.

Richards, R. \& Elms, D. G. (1992). Seismic passive resistance of tied-back walls. J. Geotech. Engng 118, No. 7, 996-1011.

Steedman, R. S. \& Zeng, X. (1990). The influence of phase on the calculation of pseudo-static earth pressure on retaining wall. Géotechnique 40, No. 1, 103-112, http://dx.doi.org/10.1680/ geot.1990.40.1.103.

Vucetic, M. \& Dobry, R. (1991). Effect of soil plasticity on cyclic response. J. Geotech. Geoenviron. Engng 117, No. 1, 89-107.

Wang, J. H., Xu, Z. H. \& Wang, W. D. (2010). Wall and ground movements due to deep excavations in Shanghai soft soils. J. Geotech. Geoenviron. Engng 136, No. 7, 984-994.

Zeng, X. (1990). Modelling the behaviour of quay walls in earthquakes. $\mathrm{PhD}$ thesis, University of Cambridge, Cambridge, UK.

Zeng, X. \& Steedman, R. S. (1993). On the behaviour of quay walls in earthquakes. Géotechnique 43, No. 3, 417-431, http:// dx.doi.org/10.1680/geot.1993.43.3.417.

Zeng, X. \& Steedman, R. S. (2000). Rotating block method for seismic displacement of gravity walls. J. Geotech. Geoenviron. Engng 126, No. 8, 709-717.

Zienkiewicz, O. C., Bianic, N. \& Shen, F. Q. (1988). Earthquake input definition and the transmitting boundary condition. In Conference on advances in computational non-linear mechanics (ed. I. St Doltnis), pp. 109-138. Berlin, Germany: Springer. 